\title{
Reply to letter to the editor: "Safety of lymphocytes immunotherapy during the COVID-19 outbreak in Wuhan, China"
}

\author{
Marcelo Borges Cavalcante ${ }^{1,2} \cdot$ Manoel Sarno $^{3} \cdot$ Edward Araujo Júnior $^{4} \cdot$ Fabricio Da Silva Costa $^{5} \cdot$ Ricardo Barini $^{6}$
}

Received: 10 September 2020 / Accepted: 28 September 2020 / Published online: 13 October 2020

(c) Springer-Verlag GmbH Germany, part of Springer Nature 2020

\section{Dear Editor,}

It was with great interest that we read and analyzed the letter to the editor of Xiang et al. The authors presented initial outcomes on the safety of lymphocyte immunotherapy (LIT) in a group of patients diagnosed with alloimmune recurrent miscarriage (RM) during November 1, 2019-January 17, 2020 in Center of Reproductive Medicine, Tongji Medical College, Huazhong University of Science and Technology.

Coronavirus Disease 2019 (COVID-19) was first described in China, in late December 2019, as a new severe acute respiratory syndrome caused by a new coronavirus called severe acute respiratory syndrome coronavirus 2 (SARS-CoV-2) [1]. The transmission of SARS-CoV-2 occurs via the respiratory tract through droplets; however, other forms of transmission are possible [1]. Studies evaluating biodistribution of SARS-CoV-2 revealed that bronchoalveolar lavage fluid specimens showed the highest positive rates (14 of $15 ; 93 \%)$, followed by sputum $(72 / 104 ; 72 \%)$, nasal swabs $(5 / 8 ; 63 \%)$, fiber bronchoscope brush biopsy $(6 / 13 ; 46 \%)$, pharyngeal swabs $(126 / 398 ; 32 \%)$, feces

Edward Araujo Júnior

araujojred@terra.com.br

1 Department of Gynecology and Obstetrics, University of Fortaleza (UNIFOR), Fortaleza, CE, Brazil

2 CONCEPTUS - Reproductive Medicine, Fortaleza, CE, Brazil

3 Department of Gynecology and Obstetrics, Federal University of Bahia (UFBA), Salvador, BA, Brazil

4 Department of Obstetrics, Paulista School of Medicine-São Paulo Federal University (EPM-UNIFESP), Rua Belchior de Azevedo, 156 apto. 111 Torre Vitoria, São Paulo, SP CEP 05089-030, Brazil

5 Department of Obstetrics and Gynecology, Ribeirão Preto Medical School - University of São Paulo (FMRP-USP), Ribeirão Prêto, SP, Brazil

6 Department of Obstetrics and Gynecology, State University of Campinas (UNICAMP), Campinas, SP, Brazil
$(44 / 153 ; 29 \%)$, and blood $(3 / 307 ; 1 \%)$, while another study detected SARS-CoV-2 in 40\% (6/15) of blood specimen $[1,2]$. Therefore, there is the possibility of transmission of COVID-19 by couples undergoing LIT.

LIT was proposed to treat couples with RM of unknown cause in the early 1980s, with encouraging outcomes [3, 4]. The LIT was first proposed by Taylor and Faulk, it was consisted of the transfusion of leukocytes isolated from the partner's blood [3]. Mowbray et al. published the first randomized controlled trial with significant increase in birth rate in RM group treated with LIT (17/22, 77\% versus $10 / 27$, $37 \%, p=0.01)$. They used a lymphocyte concentrate prepared from the partner's blood and applied by three routes, intravenously, intradermal, and subcutaneous routes. In 1999, Ober et al. questioned the effectiveness of LIT [4].

The use of LIT was limited to research protocols in the United States and in other countries around the world after the systematic review and meta-analysis of the Cochrane Library published in 2001 (the treatment effect on the live birth rate was not significant, with an OR of 1.22 and a CI of 0.89-1.69) [5]. However, over the past 2 decades, many researchers have suggested that LIT is an effective and safe treatment, provided that strict criteria for selecting couples to be treated, serological control for infectious diseases, and safety procedures in the laboratory during the preparation of the immunization [6-9].

To assess the risk of contamination by SARS-CoV-2, Xiang et al. followed up patients undergoing LIT weekly up to 4 months. The authors found no case of COVID-19 in the group undergoing treatment, while Wuhan's overall infection rate is $0.55 \%$. However, some points were not clear about the LIT protocol during this pandemic period. Were couples assessed [clinically, serology (IgM, IgA, and/or IgM) for SARS-CoV-2, or by RT-PCR for SARS-CoV-2] before immunizations? In the phone follow-up after the LIT, how was the evaluation performed? Which signs and symptoms were questioned? How to evaluate possible asymptomatic 
cases? Was there any laboratory follow-up of patients after LIT?

Recently, an international collaboration of experts who have been working in the field of reproductive immunology debated the use of immunotherapies in patients with reproductive failures during the pandemic by COVID- 19 . The authors commented that due to possible transmission of SARS-CoV-2 via lymphocyte donors' blood and a lack of knowledge about the impact of LIT on the immune response in COVID-19 cases, the LIT should be discontinued until there is evidence of safety and a better understanding of the COVID-19 immune response [10].

Therefore, more studies such as Xiang et al. must be carried out to assess the safety of LIT in this pandemic period, as well as to clearly understand the effect of this therapy on the immunopathology of COVID-19.

\section{Compliance with ethical standards}

Conflict of interest The authors declare that they have no conflict of interest.

\section{References}

1. Wang W, Xu Y, Gao R et al (2020) Detection of SARS-CoV-2 in different types of clinical specimens. JAMA. https://doi. org/10.1001/jama.2020.3786
2. Zhu N, Zhang D, Wang W et al (2020) A novel coronavirus from patients with pneumonia in China, 2019. N Engl J Med 382:727-733

3. Taylor C, Faulk WP (1981) Prevention of recurrent abortion with leucocyte transfusions. Lancet 2:68-70

4. Mowbray JF, Gibbings C, Liddell H et al (1985) Controlled trial of treatment of recurrent spontaneous abortion by immunisation with paternal cells. Lancet 1:941-943

5. Wong LF, Porter TF, Scott JR (2014) Immunotherapy for recurrent miscarriage. Cochrane Database Syst Rev 2014:Cd000112

6. Cavalcante MB, Sarno M, Araujo Júnior E et al (2017) Lymphocyte immunotherapy in the treatment of recurrent miscarriage: systematic review and meta-analysis. Arch Gynecol Obstet 295:511-518

7. Cavalcante MB, Sarno M, Niag M et al (2018) Lymphocyte immunotherapy for recurrent miscarriages: predictors of therapeutic success. Am J Reprod Immunol 79:e12833

8. Sarno M, Cavalcante MB, Niag M et al (2019) Gestational and perinatal outcomes in recurrent miscarriages couples treated with lymphocyte immunotherapy. Eur J Obstet Gynecol Reprod Biol X 3:100036

9. Liu Z, Xu H, Kang X et al (2016) Allogenic lymphocyte immunotherapy for unexplained recurrent spontaneous abortion: a metaanalysis. Am J Reprod Immunol 76:443-453

10. Kwak-Kim J, Ota K, Sung N et al (2020) COVID-19 and immunomodulation treatment for women with reproductive failures. $\mathrm{J}$ Reprod Immunol 141:103168

Publisher's Note Springer Nature remains neutral with regard to jurisdictional claims in published maps and institutional affiliations. 